\title{
Os jesuítas no Marañón: Pablo Maroni e sua proposta para o desenvolvimento das Missões de Maynas
}

\author{
The Jesuits in Marañon: Pablo Maroni and his proposal for the development of the \\ Maynas Missions
}

\author{
Roberta Fernandes Santos \\ Universidade de São Paulo (USP), São Paulo, SP, Brasil \\ Secretaria de Educação do Estado de São Paulo
}

\begin{abstract}
RESUMO: As Missóes de Maynas foram fundadas pelos jesuítas em 1638, em uma parte do território que hoje em dia conhecemos como Amazônia. Os missionários jesuítas foram os responsáveis pela pacificação e redução da maior parte dos índios do Marañón e seu projeto de ocupação foi o único considerado viável para aquela região periférica do império colonial espanhol. Sendo assim, o estudo da experiência jesuítica nas Missões de Maynas pode fornecer-nos dados importantes para a compreensão da dinâmica colonial em outros territórios também considerados marginais ou periféricos.

Neste artigo, apresentamos o processo de fundação e constituição das Missões de Maynas, realizamos um debate com a bibliografia sobre as missóes jesuíticas e sobre a especificidade da escrita na Companhia de Jesus e analisamos parte do documento Noticias Auténticas del Famoso Rio Marañón, escrito pelo jesuíta Pablo Maroni entre 1730 e 1738. Destacamos sua proposta para o desenvolvimento das Missóes de Maynas e a viabilidade desse projeto.
\end{abstract}

PALAVRAS-CHAVE: Jesuítas. Missóes. Maynas. Indígenas.

ABSTRACT: The Missions of Maynas were founded by the Jesuits in 1638, in a part of the territory that we know as Amazon. The Jesuit missionaries were responsible for the pacification and reduction of most of the Marañón indians and their occupation project was the only one considered viable for that peripheral region of the Spanish colonial empire. Thus, the study of the Jesuit experience in the Missions of Maynas can provide us with some

\footnotetext{
*Doutora em História Social pela Pontifícia Universidade Católica de São Paulo (PUCSP), São Paulo, SP, Brasil. Doutoranda em Educação pela Universidade de São Paulo (USP), São Paulo, Brasil. Professora da Secretaria da Educação do Estado de São Paulo. E-mail: robertafdsantos@gmail.com. ORCID: https://orcid.org/0000-0002-9329-7573.
} 
data for the understanding of colonial dynamics in other territories also considered marginal or peripheral. In this article, we present the process of founding and constituting of the Missions of Maynas, conducting a debate with the bibliography on Jesuit missions and on the specificity of writing in the Society of Jesus and analyzing part of the document Noticias Auténticas del Famoso Rio Marañón, written by Pablo Maroni between 1730 and 1738. We highlight his proposal for the development of the Maynas Missions and the viability of this project.

KEYWORDS: Jesuits. Missions. Maynas. Indigenous.

\section{Os jesuítas e as Missões de Maynas}

Os jesuítas tiveram um papel de destaque entre os primeiros exploradores do que hoje em dia conhecemos como Amazônia. Nestas regióes de densa floresta e distantes dos grandes centros coloniais, os missionários da Companhia de Jesus representavam, muitas vezes, a única presença europeia.

Havia, por parte dos colonos de Lima e Quito, um certo desinteresse pela colonização de tais territórios. Dentre os fatores que justificam essa falta de interesse se destacam: a dificuldade de acesso à região de floresta, o clima quente e úmido, a diversidade e a hostilidade dos grupos indígenas, fator que praticamente impedia seu aproveitamento como mão de obra. Essas razões contribuíram para que os territórios no Marañón ocupassem posição marginal ou periférica no sistema colonial espanhol. Assim, a alternativa considerada mais viável para a ocupação de tais territórios foi a implantação de missóes religiosas, segundo Fernando Torres Londoño:

En ese contexto, las autoridades del virreinato de Perú entendieron que las misiones atendidas por órdenes religiosas eran la mejor forma de expandir las fronteras y entrar en esas selvas, con lo que se cumplía también con la obligación de convertir las naciones indígenas al evangelio. (TORRES LONDOÑO, 2012, p. 186)

Essa ideia concretizou-se no início do século XVII, após a fundação de algumas cidades na região conhecida como pé-de-monte andino e a ocorrência das primeiras rebelióes indígenas na região, dentre as quais, destaca-se a rebelião dos índios Mayna.

Em 1616, durante uma expedição de captura de índios, os soldados espanhóis contataram os índios da etnia Mayna que, "voluntariamente", seguiram juntamente com eles até a cidade de Santiago de las Montañas, onde foram recebidos pelo governador Diego Vaca de la Vega, que logo percebeu a possibilidade de utilizar a mão de obra dos índios Mayna para o trabalho nas encomiendas. Então, Vaca de la Vega solicitou ao Vice-rei peruano, Francisco de Borja y Aragon, a permissão para fundar uma cidade no território daquele grupo indígena.

A permissão foi concedida em 1619 e a cidade recebeu o nome de San Francisco de Borja, em homenagem ao Vice-rei. Diego Vaca de la Vega tornou-se o primeiro Governador da Província de Maynas, cujos limites se definiam:

[...] desde el estrecho del Pongo y principio del raudal que llaman de Manseriche, todo este río abajo, y los demás que entran a él de la una banda y otra hasta donde se acaba la provincia de los indios naturales maynas; que linde, por mano derecha como se va río abajo, con 
la provincia de Xeveros, y, por mano izquierda, linde con la Cordillera general hasta que se divide con el término de la ciudad de Macas, gobernación de los Quijos, y el río abajo, hasta donde hubiere los dichos indios Maynas, inclusive la laguna de Mayna, y de donde se origina la dicha provincia y la laguna de Maracayo, con declaración que la Cordillera que divide el río, por el dicho estrecho, por donde quiera que caminare de una parte u otra, divida el término de esta ciudad con la de Santiago y la Nieva. (PORRAS, 1987, p. 23)

A partir da fundação de San Francisco de Borja, os índios Mayna e de outros grupos que habitavam as regióes próximas, passaram a ser controlados de acordo com o sistema das encomiendas. A situação pacífica na cidade não durou muito, logo ocorreu uma série de levantes indígenas contra o caráter violento do sistema de trabalho nas encomiendas. $\mathrm{Na}$ tentativa de conter essas rebelióes, o governador de Borja, Pedro Vaca de la Cadena, solicitou o envio de missionários jesuítas para a região. Em 1638, chegaram Gaspar de Cujia e Lucas de la Cueva, conforme o relato do padre Figueroa:

Llegaron los Padres Gaspar de Cujia y Lucas de la Cueva, con el Governador D. Pedro Baca de la Cadena [...], á esta ciudad de San Francisco de Borja á los seis de febrero del año de 1638, [...], y tres años después del alçamiento referido. Cobraron noticia del estado de la tierra, castigo y reducion que se proseguia de los rebelados maynas; y por ser ya cerca de Quaresma trataron de obrar lo que á la saçon instava, que eran sermones, exemplos, confessiones y que cumpliessen con la Iglesia [...]. (FIGUEROA, 1986, p. 157)

Podemos afirmar que foram os jesuítas os responsáveis pela pacificação e redução da maior parte dos índios da floresta e pela ocupação daqueles territórios periféricos. De acordo com Torres Londoño:

La postura de los jesuitas de negociar con los indios y no solamente reprimirlos, la propuesta de una catequesis fundamentada en la presencia permanente de misioneros, su habilidad para presentarse como la mejor forma de presencia española y cristiana entre los indios y la lealtad con la familia Vaca de la Vega, a la que apoyaba en su continuidad en la gobernación, hicieron que el gobernador y sus sucesores favorecieran un modelo de misión fundado en el contacto con diversas naciones y el establecimiento de reducciones distantes y precarias. (TORRES LONDOÑO, 2012, p. 186)

Dessa maneira, consolidou-se a presença dos membros da Companhia de Jesus na região do Marañón e, ao conjunto das reduçóes por eles fundadas no período de 1638 a 1767, deu-se nome de Missões de Maynas.

A atividade missionária dos jesuítas, inclusive em Maynas, apesar de atender aos objetivos particulares da Companhia de Jesus, também colaborou com o projeto colonial espanhol e com a expansão de suas fronteiras. Silva e Nascimento afirmam que “[...] ainda que as missóes tivessem uma tarefa eminentemente religiosa, estas dependiam dos interesses e das pretensões políticas da Coroa espanhola" (SILVA; NASCIMENTO, 2017, p. 143). Dessa forma, a chamada Província de Maynas expandiu-se para além de San Francisco de Borja, abarcando todo o território por onde os jesuítas fundaram reduções e as designaram como parte das Missões de Maynas; segundo Golob:

In the $17^{\text {th }}$ and $18^{\text {th }}$ centuries the Governación of Mainas, as defined by the colonial government, meant the section of the lowlands that was just north and south of the Marañon and 
Amazon rivers, plus adjacent pieces of the tributaries: the Pastaza, Huallaga, Tigre, Ucayali, Napo, etc. The Governor of Mainas had jurisdiction for only this region. The Jesuits, however, were working with a larger concept of the region. They had been awarded the Curato of Archidona on the upper Napo River in the $17^{\text {th }}$ century, and used this as a base to explore an found missions on the Aguarico, Pastaza, Curaray and adjacent river. Politically this section of the lowlands came under the jurisdiction of the Governación and Governor of Quijos, not Mainas. However, in their documents the Jesuits refer to their work in and around Archidona as either part of the Curato of Archidona or as part of Mainas. The distinction was insignificant for the Jesuits. The two regions had continual interconnection and interaction with each other, and for all practical purposes the Curato of Archidona was treated as part of Mainas. (GOLOB, 1982, p. 36)

O espaço ocupado pelas Missóes de Maynas estendeu-se por toda a região do alto Amazonas, nas áreas abarcadas pelos rios Marañón, Huallaga, Ucayali, Napo e Amazonas. Podemos afirmar que o uso da denominação "Missóes de Maynas”, tanto pelos jesuítas quanto pelas demais autoridades coloniais, compunha uma estratégia de apropriação do território. Os jesuítas estavam a serviço da coroa espanhola, consequentemente, suas missóes estavam submetidas ao império espanhol, dessa forma, por onde elas se estendessem, estender-se-iam também as posses da Espanha.

Silva e Nascimento, em suas análises sobre as missões jesuíticas no Oiapoque e em Chiquitania, apontaram para a função de "sentinelas das fronteiras" desempenhada pelas missóes em áreas onde o domínio espanhol tocava territórios pertencentes a outras monarquias europeias (SILVA; NASCIMENTO, 2017, p. 141-143). Segundo os autores, “[...] pode-se afirmar que as autoridades estatais espanholas se utilizaram dos trabalhos missionários para subjugar diversos grupos indígenas, ocupar efetivamente as Américas e proteger fronteiras" (SILVA; NASCIMENTO, 2017, p. 143). No caso específico das Missões de Maynas, explica Torres Londoño:

Los documentos, de modo recurrente, ponen en evidencia el papel desempeñado por las misiones de Maynas como único obstáculo español que oponía resistencia al avance portugués en dirección al Perú, argumento muchas veces esgrimido para justificar que las mismas merecerían todo el apoyo de las autoridades, tanto de virreyes como de gobernadores y ministros. (TORRES LONDOÑO, 2012, p. 190)

Ao total, 161 jesuítas trabalharam como missionários em Maynas - destes, 62 eram nascidos na América e os demais possuíam nacionalidades europeias (espanhóis, alemães, italianos, portugueses, franceses e húngaros) - a maioria era composta por homens adultos, entre 25 e 45 anos. Durante o século XVII, o número de missionários em atividade não ultrapassou dez. Já no período posterior, durante a primeira metade do século XVIII, esse número chegou a vinte missionários em Maynas; depois de 1752, os números foram ainda maiores, chegando, em 1767, a 28 missionários, momento em que ocorreu a expulsão dos jesuítas (GOLOB, 1982, p. 75-78). Após a expulsão, segundo Martin Rubio: “[...] todo prácticamente desapareció al ser expulsada la Compañía de Jesús [...]. Desde este momento, Maynas se constituyó en un verdadero problema para la Corona española, puesto que los portugueses invadían y se apropiaban de gran parte de sus bosques [...]” (MARTIN RUBIO, 1991, p. X).

As dificuldades encontradas pelos missionários nesse empreendimento foram muitas. Em primeiro lugar, havia os empecilhos físicos e geográficos: o clima quente e úmido, caminhos 
tortuosos por montanhas, costas inclinadas, regióes pantanosas, rios caudalosos, insetos e animais desconhecidos.

Outro fator importante para a análise das Missões de Maynas foi o alastramento das epidemias que provocavam a morte de uma enorme quantidade de população nativa. As doenças que mais afetaram os índios foram a varíola, a rubéola e a gripe.

Havia também a barreira cultural. Os missionários encontravam-se rodeados por uma quantidade enorme de grupos indígenas que possuíam línguas e culturas diversas entre si e totalmente diferentes da europeia. Além disso, eram frequentes as insurreições indígenas, e não eram raras as vezes em que missionários acabavam sendo mortos nessas rebelióes (TORRES LONDOÑO, 2012, p. 187). Algumas dessas situações foram registradas por Maroni:

La Compañía de Jesús tiene en este gran río una muy extendida laboriosa y A postólica Misión, [...]. Se pasa allí por caminos muy arduos y la gran parte a pie [...], recorriendo distancias largas y azarosas hacia sus reducciones. Los salvajes han matado en estas a los siguientes padres [...] Vitorio de Figuera en la boca del río Apena cerca del Huallaga en 1660; Padre Pedro Suarez en Maynas en 1660; Padre Agustín Hurtado en Roamaynas en 1677; Padre Henrique Pictaron Piros en 1695, y en este año de 1707 han llegado repetidas noticias que los salvajes han asesinado al padre Nicolás Durango en Gayes. (MARONI, 1988, p. 525)

As rebeliões indígenas eram frequentes em Maynas. Esses levantes podiam ser provocados por vários motivos - pelo uso de métodos violentos na conversão, pela proibição dos antigos costumes e rituais indígenas, pelo não fornecimento de objetos de metal como facas, agulhas e machados, entre outros; de modo geral, podemos afirmar que a rebelião indígena representava um desequilíbrio na relação entre os missionários e os índios, pois as alianças somente eram mantidas enquanto eram proveitosas para ambos os grupos em contato. A partir do momento em que um grupo se via em desvantagem, nesse caso, o indígena, as rebelióes eclodiam e, na maioria das vezes, seu desfecho era violento, culminando com o assassinato dos missionários ou com o massacre dos revoltosos.

Ainda há que se dizer que, embora representassem a autoridade colonial naquelas áreas marginais do império, os jesuítas contavam com poucos incentivos, seja das autoridades locais ou da coroa espanhola, embora esse auxílio estivesse regulamentado por Cédula Real, como é o caso, por exemplo, do envio de escolta armada para acompanhar os missionários em suas entradas; sobre isso, escreveu Maroni:

[...] conforme está tambien cautelado por algunas ordenes del Superior Gobierno y cédulas de S.M., especialmente por una fecha en 15 de Julio de 1683, [...], en que manda al Presidente y Real Audiencia de Quito, que en caso que pareciera conveniente enviar cabo que sirva de escolta á los religiosos misioneros que entraren á estas conversiones [...]. (MARONI, 1988, p. 202)

Além da escolta, os missionários deveriam receber duzentos pesos anuais em produtos como roupas, alimentos e objetos de ferro. Esse auxílio, porém, era incerto; os produtos constantemente chegavam com atraso, ou até mesmo nem chegavam, tendo o missionário que ir retirá-los em Quito, nos casos de extrema necessidade.

Com a finalidade de garantir o próprio sustento, o missionário podia também utilizar-se da mita, sistema de trabalho em que alguns índios eram forçados a cuidar da alimentação do missionário e realizar serviços domésticos na casa principal e na igreja da missão. 
O missionário não podia deixar a missão sem a autorização de seu Superior. Mesmo que o missionário quisesse solicitar algo à Audiência, ele deveria primeiro se manifestar ao seu Superior e este procuraria obter a permissão junto ao Padre Provincial ou ao Padre Reitor do Colégio de Quito. Toda decisão de maior importância - como a fundação de novas reduções, a realocação dos índios ou a construção de uma igreja - deveria passar pelo crivo do Superior das Missões.

Era também obrigação do Padre Superior realizar, anualmente, uma visita por todo o complexo missionário de Maynas. Nessas visitas, o Superior aconselhava os missionários, tanto em questóes religiosas como temporais, auxiliava na tomada de decisóes, verificava o estado das igrejas e dos ornamentos usados nos rituais católicos, revisava os livros de batismos, casamentos e óbitos, dando particular atenção ao registro do número de convertidos.

Mesmo contando com parcos recursos financeiros e raros auxílios das autoridades coloniais, a expansão dos jesuítas pelos territórios da bacia amazônica não foi fruto de mera contingência. A fundação dos aldeamentos em Maynas seguiu um projeto organizado que visava à ocupação de espaços estratégicos às margens dos rios, facilitando, assim, os deslocamentos pelas missóes e a comunicação entre os missionários.

Fundamentando-se nesse plano de avanço, os jesuítas promoveram uma gradual ocupação do território, partindo de San Francisco de Borja e rumando na direção leste. A primeira área ocupada, entre os anos de 1638 e 1683, abarcava a região dos rios Huallaga, Marañón, Napo, Aguarico e Putumayo; foi um período marcado pela insuficiência de missionários. Em 1684, com a chegada de jesuítas de diversas nacionalidades, iniciou-se a ocupação da área central do rio Marañón, chegando até seu desemboque no rio Amazonas; este foi o momento de auge das Missóes de Maynas, que durou até o ano de 1728. Após esse período, os jesuítas empreenderam várias tentativas de penetração pelos rios Madeira e Negro, mas o avanço português dificultava o trabalho missionário.

As missões foram fundadas, preferencialmente, nas margens ou próximas aos rios, para facilitar o deslocamento dos missionários e a comunicação entre as reduções. Essa foi uma das justificativas utilizadas pelos jesuítas de Maynas para promoverem o deslocamento dos grupos indígenas para as reduçôes; segundo Downes:

Para no perder la salvación de miles de almas la única solución [...] fue concentrar las diferentes etnias y grupos en reducciones comunes. Se trató de una solución pragmática. La esperanza de los jesuitas fue concentrar su trabajo en misiones centrales atrayendo, invitando, "cazando" y recapturando los nativos. En un primer momento poblaron una reducción con grupos pertenecientes a las mismas etnias. Después intentaron reunir también a diferentes tribus en un mismo pueblo. Pero la realidad se mostró complicada. La concentración de diferentes grupos tribales y etnias en una misma reducción creó problemas de convivencia. (DOWNES, 2005, p. 179-180)

O deslocamento de grupos indígenas para as reduções e o agrupamento de populações pertencentes a diferentes etnias foi uma estratégia amplamente utilizada pelos jesuítas em diversos territórios. Serviu como modelo o trabalho missionário realizado pelos inacianos na Província jesuítica do Paraguai (SILVA; NASCIMENTO, 2017, p. 144). Porém, essa prática nem sempre gerou os resultados esperados. Nas Missões de Maynas, como apontou Downes, essa estratégia acarretou problemas de convivência entre grupos étnicos diferentes. Silva e Nascimento apontam que, nas missóes jesuíticas do Oiapoque, essa prática também mostrou-se problemática: "Dentre as 
dificuldades encontradas podem ser citadas a diversidade linguística dos povos indígenas, problemas de comunicação e mortandades provocadas por doenças." (SILVA; NASCIMENTO, 2017, p. 147).

A diversidade linguística das populações indígenas era mais um dos desafios encontrados pelos jesuítas. Eram nos assentamentos onde, primeiramente, o missionário deveria aprender a língua do grupo, depois transcrevê-la e enviar seus estudos a Quito, para que outros jesuítas pudessem aprender as línguas nativas antes de serem enviados às Missões de Maynas. O objetivo desse esforço era fornecer aos inacianos em trabalho missionário um instrumento prático para a pregação do Evangelho, para o ensino da doutrina cristã e para a administração dos sacramentos.

Aos índios, nas Missões de Maynas, era ensinado o quéchua como língua geral, pois os missionários consideravam que o castelhano era muito difícil para os nativos; ainda assim, o ensino do espanhol ocorria de forma sistematizada e alguns índios que o aprendiam se tornavam figuras de singular importância. Os índios intérpretes formavam um grupo social de destaque dentro da estrutura da missão, eles desempenhavam a função de mediadores dos diálogos estabelecidos entre o missionário e os membros do próprio grupo ou no contato com outros povos.

Atenção especial era destinada à educação das crianças nativas que, uma vez convertidas, auxiliariam o missionário na tarefa de convencimento dos mais velhos. A elas era ensinado o quéchua e o castelhano, o catecismo e os costumes ocidentais, considerando sempre que, futuramente, elas serviriam como instrumentos para a conversão dos adultos, como intérpretes nas confissóes ou em outras atividades comunicativas.

Em Maynas, os índios eram incentivados a realizar as atividades conforme os padróes europeus de civilização. Deveriam costurar suas roupas, fabricar e pintar suas casas, plantar e colher seus alimentos, manter o espaço limpo, frequentar as missas e seriam privados de seus antigos costumes e rituais. Cabe a ressalva de que, na prática, a situação era um tanto diferente. Não foram raras as vezes nas quais os missionários tiveram que aceitar certo afrouxamento das regras a fim de evitarem fugas, levantes e garantirem a própria sobrevivência. Segundo Silva e Nascimento:

Além disso, as estratégias de resistências indígenas foram várias, o que forçou a flexibilização das ações missionárias. Nas reduções não só os indígenas, mas também os jesuítas foram transformados, metamorfoseados, em processos de mediação e de ressignificação em que ambos os grupos reelaboraram suas próprias identidades e pautas culturais. (SILVA; NASCIMENTO, 2017, p. 151-152)

Podemos concluir que a introdução do elemento estrangeiro - o missionário - e de seu modo de vida resultou em um impacto profundo para a vida das populaçóes indígenas de Maynas. Os grupos nativos que passaram pela experiência das missões, sofreram transformaçóes substanciais em todos os aspectos de sua vida. Torres Londoño e Martins afirmam que esses grupos desenvolveram mecanismos próprios para a manutenção de seus símbolos e práticas culturais, por meio de uma refundação das suas realidades. Assim como também os missionários realizavam constantemente a leitura e a absorção das alteridades (TORRES LONDOÑO; MARTINS, 2014, p. 210-211).

Ainda há que se considerar que as Missões de Maynas sofreram com os ataques externos. Ao longo de todo seu período de existência, essas missões foram ameaçadas pelos “assaltos” portugueses que visavam à captura de índios e à expansão de seus territórios naquela área de fronteira. O declínio das Missóes de Maynas ficou evidente com a expulsão dos jesuítas de todos os territórios 
espanhóis, em 1767, provocando, assim, o quase total abandono dos aldeamentos construídos pelos missionários.

\section{Apontamentos teóricos sobre as missões jesuíticas}

O principal objetivo dos jesuítas com a implantação das missóes religiosas na América não era outro senão o de submeter o índio para reduzi-lo à fé cristã e enquadrá-lo nos padrões europeus de civilização. Daí advém o termo "redução", amplamente utilizado pelos jesuítas para designar seus aldeamentos missionários. Segundo Silva e Nascimento: "As reduçôes significaram, pois, a solução encontrada pelas autoridades espanholas para modificar o habitat disperso das populações indígenas, considerado um dos maiores obstáculos para sua civilização e cristianização.” (SILVA; NASCIMENTO, 2017, p. 143).

Dessa forma, a redução era o espaço em que o cristianismo poderia atingir sua máxima extensão, abarcando, além do campo religioso, o social, o político e o econômico. Portanto, a missão ou redução religiosa tinha por objetivo promover a total transformação cultural dos habitantes do Novo Mundo. Segundo Melià Lliteras: "Reducción es palabra desagradable que suena a empequeñecimiento y disminución. Trae también consigo la sospecha de sujeción y manipulación.” (MELIÀ LLITERAS, 1991, p. 213).

Entretanto, o modelo reducional idealizado pelos jesuítas e colocado em prática nas Missóes de Juli, por exemplo, mostrou-se impraticável em outros espaços coloniais, dentre eles, citamos, por suas semelhanças, as Missóes de Maynas, Mojos e Chiquitos; como demonstram Torres Londoño e Martins:

Em presença dessas incertezas missionárias, os jesuítas fundamentaram um projeto de evangelização para a região de Maynas, Mojos e Chiquitos que se baseou nos modelos já implantados em algumas regióes da América Portuguesa nos séculos XVI e XVII, mas que também levou em conta as especificidades das regiôes a serem catequizadas - espaços que eram marcados por um baixo número de missionários, pela diversidade de povos e línguas nativas, por um extenso espaço geográfico, por zonas com densas florestas e por uma locomoção missionária feita, essencialmente, por vias fluviais. (TORRES LONDOÑ; MARTINS, 2014, p. 202).

De acordo com Fernando Torres Londoño, três aspectos determinavam as principais particularidades das Missões de Maynas: o imenso território em que atuavam os jesuítas, a diversidade cultural e linguística dos povos indígenas da região e o reduzido número de jesuítas disponíveis para o trabalho missionário naquela área (TORRES LONDOÑO, 2011, p. 342).

Sendo assim, o modelo inicial foi adaptado às condições particulares de cada região. Segundo Cristina Pompa: “[...] a experiência da missão fazia que cada vez mais a prática de evangelização se afastasse do ideal inaciano e procurasse estratégias locais de realização” (POMPA, 2003, p. 76).

Outro ponto importante a ser evidenciado é que, por vezes, o modelo reducional idealizado pelos jesuítas distanciava-se dos objetivos econômicos do projeto colonial espanhol que, visando a atender aos interesses dos colonos, aceitava diversas formas de exploração do trabalho indígena; os jesuítas, ao contrário, ofereciam nas missóes um espaço alternativo de catequização e conversão. Convém considerar que a proteção oferecida pelos jesuítas no universo reducional, embora tenha contribuído para conter as investidas de outros agentes coloniais contra as populações indígenas, 
também foi responsável por privá-las de uma vida independente com uma organização social, política e econômica autônoma (SILVA; NASCIMENTO, 2017, p. 143).

Embora as missões religiosas tenham representado uma alternativa ao trabalho forçado, elas nunca se desvencilharam completamente do projeto colonial, pois se constituíam como uma parte dele. As atitudes dos missionários nas reduções - a disciplina imposta aos índios, os deslocamentos de grupos e o reordenamento das aldeias, a restrição da liberdade, a imposição de novas formas de trabalho e a extirpação dos costumes, religióes e tradições indígenas - sempre foram reflexo de um projeto maior de conquista que visava a transformar a população indígena, sobretudo em mão de obra. De acordo com Melià Lliteras:

Lo cierto es, sin embargo, que por detrás de esa formulación humanística, la reducción estaba destinada a integrar a los indios dentro del sistema colonial, colocar mano de obra al servicio del encomendero o patrón. La reducción, en muchos casos comenzaba donde terminaba la conquista por las armas; cuando los recursos militares eran escasos o cuando la capacidad de resistencia indígena se hacía sentir, la reducción fue un medio de pacificación. (MELIÀ LLITERAS, 1991, p. 214)

Diante desse evidente caráter ambíguo da redução jesuítica, é fácil deduzir que o modelo de missão religiosa idealizado inicialmente pela Companhia de Jesus não se concretizou completamente em Maynas. Por mais que os jesuítas alcançassem determinados êxitos por meio do trabalho missionário - como promover deslocamentos de grupos inteiros, impor certo reordenamento nos aldeamentos, estabelecer novas regras para as atividades agrícolas e proibir certos rituais - os grupos indígenas tinham a consciência de que a total transformação de seus costumes acarretaria a descaracterização de sua identidade.

Maria Cristina Bohn Martins destaca a ambiguidade de funções das missões religiosas que ora pendiam para a satisfação dos interesses coloniais e ora dos espirituais; no entanto, é interessante analisar outra função cumprida pelas reduções:

As chamadas "reducionais" através das quais povos indígenas americanos foram reunidos em "pueblos" de acordo com a legislação espanhola, costumam ser definidas por sua dupla dimensão: elas se constituíram em um modelo de evangelização posto em prática por algumas Ordens religiosas, mas também foram um instrumento de controle da monarquia sobre os habitantes de certas áreas de fronteira. (MARTINS, 2012, p. 216)

Sem dúvida, as Missões de Maynas atuaram no controle das populações das áreas de fronteiras, ainda mais se considerarmos o quanto estas foram instáveis ao longo de todo o período colonial, o que possibilitou que se realizasse o contrabando de mercadorias e metais preciosos. Silva e Nascimento afirmam que: "Essas fronteiras foram permeáveis a tal ponto que as populaçóes de um lado e de outro realizavam comércio e praticavam contrabando, fato verificado em todo o continente americano" (SILVA; NASCIMENTO, 2017, p. 146).

Assim, em áreas nas quais o controle exercido pelas autoridades civis e militares era muito frágil, ou até mesmo inexistente, foram os missionários os representantes da monarquia espanhola, e suas missões, as responsáveis por garantir o controle político e administrativo, além de promoverem a defesa desses territórios de fronteira. 
Com a finalidade de manter o melhor funcionamento possível das missóes e evitar a ocorrência de rebeliões indígenas, restava, então, aos missionários, a alternativa de uma conversão "parcial”, que mantivesse alguns elementos da cultura indígena; por exemplo, em algumas das missões, os caciques continuaram responsáveis pela organização política e social, embora devessem submissão à autoridade do missionário. Situação semelhante ocorreu nas missões do Oiapoque, Silva e Nascimento afirmam que: "Ao distribuir presentes, os jesuítas eram ressignificados pelos indígenas por tal prática, associando-se os missionários aos próprios líderes. Por isso, tinham atitudes de respeito e confiança em relação aos padres e não, exatamente, de submissão.” (SILVA; NASCIMENTO, 2017, p. 153-154).

Os jesuítas utilizaram também outra estratégia de controle cultural dos costumes indígenas ao se apropriarem de algumas características da religiosidade nativa, introduzindo nos ritos evangélicos cristãos o canto, a dança e até instrumentos musicais indígenas, destituindo, dessa maneira, esses elementos de seus significados tradicionais (MELIÀ LLITERAS, 1993, p. 112-114).

Cristina Pompa faz uma análise interessante desses processos de incorporação de elementos indígenas na catequese cristã. Segundo a autora, a religião foi duplamente utilizada como instrumento de tradução, tanto do universo mítico cristão para o indígena, como em sentido inverso, do mundo simbólico indígena para o universo europeu.

O esforço missionário concentrou-se exatamente nesta "tradução" para os códigos culturais nativos de conceitos europeus, da mesma forma como eles traduziram a si próprios nos mesmos códigos [...]. Por outro lado, esta "tradução" foi re-traduzida, ou seja, de-codificada e re-codificada pelos destinatários indígenas da mensagem cristã: o resultado foi a produção de uma religião "híbrida”, no interior de uma cultura de contato. (POMPA, 2003, p. 86)

Como apontou Pompa, o resultado obtido com esse processo de conversão religiosa e cultural foi o surgimento de uma cultura híbrida, que mesclava componentes das duas matrizes culturais que a formaram. Charles Boxer, em sua análise da colonização espanhola no Peru, ressalta que o sincretismo religioso era um aspecto comum do universo colonial, uma vez que muitos índios frequentavam regularmente a igreja e até demonstravam devoção na execução dos rituais católicos, embora continuassem a praticar suas cerimônias tradicionais com igual fervor, acrescentando-lhes, ainda, traços do catolicismo (BOXER, 2007, p. 130-131).

Em Maynas, o processo de expansão das missóes foi notoriamente violento em vários aspectos, seja no processo de deslocamento de grupos para as reduções, na aplicação de métodos violentos na catequese, ou ainda nos castigos aplicados pelos missionários e soldados nos casos de rebelião. Sobre o uso da violência nas missóes jesuíticas, Castelnau- L'Estoile indica-nos um caminho para sua compreensão. Segundo a autora, não apenas os missionários, mas todos europeus, sentiam-se apavorados diante da possibilidade de perderem as características próprias de sua cultura e sofrerem um processo de inevitável "indianização" devido à necessidade de adaptação ao meio como garantia de sobrevivência (CASTELNAU- L'ESTOILE, 2006, p. 310). De acordo com Silva e Nascimento, certamente os missionários jesuítas sofreram esse processo de "indianização":

Não somente os indígenas e suas pautas culturais foram modificados, mas os padres também tiveram que se adaptar às realidades de outros lugares e de culturas diversas. Assim, pode-se afirmar que os religiosos também foram "tocados" pelos costumes "selvagens" e metamorfoseados em suas ideias e práticas. (SILVA; NASCIMENTO, 2017, p. 154) 
Para os missionários da Companhia de Jesus, muitas vezes, o uso da violência também se justificava, pois eles acreditavam que seu trabalho era um dom concedido pela graça divina, portanto era preciso cuidar desse dom e fazê-lo frutificar, caso contrário, seriam duramente castigados. Ou seja, caso as missões não se desenvolvessem da forma esperada, os responsáveis pelo malogro do trabalho missionário não alcançariam a salvação (CASTELNAU- L'ESTOILE, 2006, p. 306).

As situações de interação entre os grupos em contato e a vivência nas Missões de Maynas mostraram que a realidade experimentada pelos jesuítas na Amazônia se distanciava cada vez mais do projeto idealizado pela Companhia de Jesus no início da colonização. Com a finalidade de desempenharem sua função missionária com êxito, atuarem conforme as regras do sistema colonial e, acima de tudo, conquistarem a almejada salvação de suas almas, os jesuítas foram impelidos a adaptarem continuamente o modelo de missão, além de seus próprios hábitos e concepções. De acordo com Maria Cristina Bohn Martins: "Foi o equilíbrio estabelecido entre a obediência, a hierarquia e a unidade de ação, de um lado, e a adaptabilidade das normas às realidades locais, de outro, que garantiu boa parte do êxito dos inacianos como missionários" (MARTINS, 2012, p. 223).

Esse processo de adaptação deixou seus reflexos no conteúdo das cartas, narrativas, dos relatos, das crônicas, e outros documentos jesuíticos. De um modo geral, os escritos produzidos pelos jesuítas no contexto colonial, além de buscarem justificativas para as alterações das práticas missionárias em determinados contextos - como ocorreu em Maynas - também articularam as vozes dos demais sujeitos envolvidos no processo de colonização, refletindo seus interesses, seus pontos de vista e suas intenções.

Portanto, para analisar tais fontes, devemos compreender suas possibilidades e seus limites dentro do contexto mais amplo em que foram produzidas e a partir das regras de escrita estabelecidas pela Companhia de Jesus.

\section{A escrita jesuítica}

A ordem religiosa denominada Companhia de Jesus foi idealizada pelo espanhol Inácio de Loyola e criada oficialmente pela Bula Regimini Militantis Ecclesiae expedida pelo Papa Paulo III, em 27 de setembro de 1540. A identidade jesuítica que fundamenta a unidade da ordem é o "nosso modo de proceder", sendo assim, todos os membros dispersos necessitam agir de uma mesma maneira, mesmo que ela não seja exatamente idêntica em todos os casos. As regras da Companhia de Jesus não são estáticas, mas dinâmicas e permitem a adaptabilidade necessária aos missionários em trabalho, praticamente, no mundo todo.

Além do "nosso modo de proceder", outros preceitos constituem o ethos institucional da ordem, são eles: os votos de pobreza, castidade, mobilidade e obediência. As missóes dependiam particularmente do voto de obediência para sua prosperidade, uma vez que os missionários, por mais distantes que estivessem do centro de controle, deveriam obedecer às ordens que chegavam através de seus superiores.

As "Constituições” eram o documento orientador das ações dos missionários. Elaboradas a partir do princípio da casuística, sua função era nortear o processo de tomada de decisões racionais, amparadas pelos preceitos de adaptação das normas e tolerância das violações. 
Mesmo com essa relativa liberdade de ação, os missionários deveriam atender à obrigatoriedade da escrita epistolar periódica. Através dela, o centro de poder da ordem, instalado em Roma, poderia acompanhar a atuação dos seus membros, onde quer que estivessem, e instruí-los, da forma mais rápida e menos custosa, sobre como atuar em determinadas situações. Era, então, através das cartas, dos informes, das crônicas e outros documentos escritos pelos missionários dispersos que o centro da ordem tomava conhecimento dos fatos e controlava o trabalho nas missóes.

Nesses documentos, os jesuítas informavam sobre o estado das missões, sobre as doações recebidas, as dificuldades materiais enfrentadas, sobre os empecilhos naturais característicos de cada ambiente onde eram instaladas as reduções, sobre a frequência das rebeliões indígenas, sobre os progressos do projeto reducional e sobre todos os demais assuntos que o missionário considerasse importante para o bom andamento de seu trabalho.

Mais do que simplesmente informar, a escrita jesuítica permitia à Companhia de Jesus manter o nível mais elevado possível de coerência entre as ações dos missionários, sendo também o meio privilegiado de integração entre seus membros, "[...] a correspondência liga não apenas os membros dispersos à cabeça do corpo, mas também estabelece uma rede horizontal de relaçóes [...].” (CASTELNAU-L'ESTOILE, 2006, p. 73). Ou seja, era através da comunicação epistolar que um missionário se mantinha ligado horizontalmente com os demais jesuítas dispersos, e verticalmente com seus superiores em Roma. Desse modo, todos os documentos jesuíticos constituem-se testemunhos da relação interna de poder entre o centro (Roma) e a periferia (missões).

O conteúdo desses documentos era apologético e retórico, pois era preciso justificar o trabalho dos missionários entre os índios, garantindo, assim, o apoio das monarquias europeias, das autoridades locais e o financiamento de seus projetos. De acordo com Silva e Nascimento, é necessário olhar essa documentação com cautela, pois sua função apologética edificava o trabalho missionário dos jesuítas: "Isso significa que os documentos possuíam o intuito de exaltar para além da realidade os trabalhos dos jesuítas e, por conseguinte, a imagem da Companhia de Jesus, quando fossem publicadas na Europa.” (SILVA; NASCIMENTO, 2017, p. 147).

Para atingir essa finalidade, era necessário que se descrevesse a experiência dos jesuítas nas mais diversas realidades em que suas missóes estavam instaladas e se registrasse os avanços da atividade missionária, uma vez que o reconhecimento do trabalho dos jesuítas por aqueles que lhes prestavam ajuda financeira dependia diretamente da publicidade de seus feitos em territórios considerados exóticos, ou inóspitos (EISENBERG, 2000, p. 50), como era o caso das Missões de Maynas.

Outra necessidade da Companhia de Jesus era garantir, constantemente, a entrada de novos membros interessados em dar continuidade ao trabalho missionário. Para isso também servia a publicidade dada aos escritos dos padres dispersos. Era preciso despertar a vocação missionária entre a juventude e o primeiro passo era convencê-los de que o trabalho missionário garantiria a salvação da alma, a partir da compreensão de que o trabalho missionário é, de fato, como a missão daquele que tem a convicção de que sua religião é a verdadeira e todas as demais, credos falsos e infundados. Assim, a vocação missionária seria, sobretudo, uma missão de conversão de "infiéis".

Ademais, ao retratarem a experiência vivida pelos missionários dispersos em territórios inimagináveis, estas cartas, quando eram publicadas na Europa, despertavam a curiosidade sobre as terras distantes e desconhecidas e encorajava outros jesuítas a apresentarem-se como voluntários para as missões. 
Outras ordens religiosas seguiram o exemplo da escrita epistolar jesuítica, primeiro por perceberem o aumento do número de membros ingressantes na Companhia de Jesus e depois, “[...] para edificar os fiéis nos países de origem e incentivá-los a se apresentar como voluntários para as missões ultramarinas” (BOXER, 2007, p. 119). Isso possibilitava, também, a construção, assim como faziam os jesuítas, da memória dos feitos de seus membros.

Visando ao cumprimento máximo dos objetivos da escrita epistolar jesuítica, foram elaboradas algumas normas para regulamentar os tipos de registros que os missionários deveriam produzir, bem como a periodicidade de escrita e de envio aos superiores. Dessa forma, a escrita das cartas pelos missionários deveria seguir dois modelos estabelecidos: as hijuelas e as cartas edificantes (EISENBERG, 2000, p. 52-55).

As hijuelas deveriam ser escritas semanalmente, eram endereçadas diretamente ao superior hierárquico do missionário e sua circulação era restrita aos membros da Companhia de Jesus. $\mathrm{O}$ conteúdo das hijuelas era variado, de um modo geral, o missionário informava seu superior sobre a localização das missóes, o número de jesuítas em atividade, as nomeações, os falecimentos, as dificuldades com a execução do projeto missionário, os fracassos e sucessos alcançados e outros assuntos particulares.

As cartas edificantes, como o nome demonstra, apresentavam as virtudes e os sucessos do trabalho missionário, pois a circulação era livre e a leitura, pública. O objetivo das cartas edificantes era promover a publicidade dos feitos “heroicos” dos missionários, despertar vocações e curiosidades, incentivar doações e financiamentos, enfim, conquistar o apoio material ou espiritual daqueles que as lessem. Eram escritas, pelo menos, a cada quatro meses, de forma sistemática e abusando da retórica. Segundo Boxer: "[...] escritas para conseguir apoio e despertar interesse no trabalho missionário, as cartas geralmente dão a impressão de que as coisas iam melhor do que de fato acontecia” (BOXER, 2007, p. 118).

À luz da bibliografia apresentada, partimos do pressuposto de que os documentos produzidos pelos jesuítas das Missões de Maynas não foram resultado de sua livre iniciativa e tampouco representavam a simples vontade de que suas experiências se tornassem públicas, mas, ao contrário, como demonstramos, esses registros eram determinados por um conjunto de regras impostas pela Companhia de Jesus.

Em seguida, analisaremos uma parte de um desses documentos, as Noticias Auténticas del Famoso Rio Maroñón ${ }^{1}$, obra escrita pelo Padre jesuíta Pablo Maroni.

\section{Pablo Maroni e sua proposta para o desenvolvimento das Missões de Maynas}

Pablo Maroni, natural de Friul, Veneto (Itália), nasceu em primeiro de novembro de 1695, entrou para a Companhia de Jesus em 28 de outubro de 1712 e sua chegada em Quito data de 1724. Após vários anos de atividade missionária em Maynas, afastou-se das missões por causa de uma enfermidade adquirida no ano de 1731. Restabeleceu-se em Santiago de La Laguna (capital das Missóes de Maynas) e, logo depois, foi para o colégio de Quito, onde começou a escrever suas Noticias. Foi convidado pelo Padre Visitador Andrés de Zárate para, acompanhado pelo padre Bastidas, supervisionar as missóes do Napo. Morreu em Guayaquil em 23 de novembro de 1757. 
As Noticias Auténticas del Famoso Rio Maroñón foram escritas por Maroni, provavelmente, entre os anos de 1730 e 1738, quando da sua interrupção. A obra está dividida em três partes. $\mathrm{Na}$ primeira parte, Noticias generales que recogió el autor siendo misionero en este río, Maroni fez uma descrição detalhada da localização e geografia dos rios, dos animais, da vegetação - inclusive apontando a possibilidade de comercializar alguns produtos da natureza local - e das populaçóes indígenas, suas línguas e seus costumes. Na segunda parte, Noticias de las misiones más antiguas del Marañón, Maroni descreveu as primeiras experiências dos missionários jesuítas no Marañón ainda em fins do século XVI e a fundação das primeiras missões em Maynas e seu desenvolvimento durante o século XVII. Na terceira parte, Noticias de las misiones más modernas del Marañón, Maroni descreveu o desenvolvimento das Missões de Maynas durante o final do século XVII e início do XVIII. Destacamos que, no terceiro capítulo desta última parte, Pablo Maroni fez a transcrição do diário do Padre Samuel Fritz e, no capítulo quarto, fez transcrições de algumas cartas do Padre Carlos Bretano, escritas já na década de 1730 (a última carta é de 1738). Sua obra, apesar de inconclusa, oferece-nos um panorama do apogeu e, logo depois, da recessão da atividade jesuítica nas Missóes de Maynas. Neste artigo, destacaremos apenas alguns momentos em que o Padre Pablo Maroni, a partir de suas experiências, fez propostas para o maior e melhor desenvolvimento das Missões de Maynas.

Padre Maroni, assim como os demais missionários de Maynas daquele momento, vivenciou todo o processo de expansão das missões jesuíticas no Marañón e, em suas Noticias, denunciou o descaso das autoridades coloniais para com a região e a situação arriscada em que se encontravam os jesuítas em trabalho missionário por aquelas partes limítrofes do império espanhol.

Padre Maroni não fugia da ideia de que a aplicação do projeto missionário seria ideal para promover a ocupação dos territórios de Maynas, pois os índios eram a maioria da população nos pueblos, por isso a importância do projeto evangelizador dos jesuítas, não apenas para formar índios cristãos, mas para transformá-los em vassalos da coroa espanhola.

$\mathrm{Na}$ sua concepção, para o bom funcionamento das missóes, seria essencial a presença de colonos espanhóis em duas frentes: a militar, compondo escoltas armadas diretamente subordinadas ao missionário, e a civil, composta por homens dispostos a viver nos pueblos.

Como dito anteriormente, é importante ressaltar que, aos missionários de Maynas, era permitido que tivessem uma escolta, de pelo menos dois soldados, para a garantia de sua segurança. Embora essa permissão estivesse regulamentada, pouco se cumpria. A necessidade da escolta para o êxito do projeto missionário era inquestionável, inclusive esse era um ponto de concordância entre todos aqueles que conheceram a realidade do Marañón e constantemente era reafirmado pelo Padre Maroni:

Añádase a esto la falta de escolta de alguna gente española que acompañe con armas defensivas a los misioneros cuando entran a provincias infieles y asista al entable de las reducciones, industriando y alentando con discreción y eficacia los nuevos moradores al trabajo de que tanto aborrecen, enseñándoles con su ejemplo a acudir a la iglesia y doctrina, obedecer y respetar al Padre; en fin, sirviéndoles de freno para que ni se atrevan a algún desacato, ni sean tan inconstantes y fáciles a volver como bestias a sus querencias y escondrijos, llevándose la herramienta y párvulos bautizados y dejando al misionero en un total desamparo. Sin esta escolta y ayuda de españoles apenas hay que esperar cosa de provecho y subsistencia en la reducción de aquellos bárbaros [...]. (MARONI, 1988, p. 414) 
Para Maroni, essa escolta também poderia ser composta por índios cristãos, e não apenas por soldados colonos, desde que a esses índios fossem dadas armas para a garantia da proteção e segurança dos missionários e de seus intérpretes. Segundo Maroni, essa situação de decadência em que se encontravam as escoltas armadas de Maynas foi se agravando com o passar do tempo:

En los primeros tiempos en que se fundaron estas misiones, como habia bastantes soldados en la ciudad de Borja y estas conquistas corrian regularmente por cuenta de los gobernadores y sus tenientes que residian en la provincia, [...], las armadas solian ser más numerosas; hoy se reducen de ordinario á 50 ó 60 indios con dos ó tres españoles de los pocos que asisten en Borja y otras reducciones, [...]. (MARONI, 1988, p. 202)

A partir dos relatos de Maroni, podemos inferir que a formação de uma escolta armada que acompanhasse os missionários em seu trabalho era de extrema importância para o bom funcionamento das missóes. Sem a presença dos soldados, os jesuítas ficavam vulneráveis em suas incursóes, principalmente pela constante ameaça de ataques dos índios ainda não reduzidos, mas também ficavam expostos, nas missóes já fundadas, aos assaltos dos colonos portugueses que promoviam entradas cada vez mais frequentes e agressivas na região.

Segundo Maroni, além da insegurança do trabalho missionário, outro problema era a dificuldade em evangelizar os índios, que insistiam em permanecer com suas antigas práticas. A questão da "inconstância" foi um tema recorrente na documentação produzida em diversos contextos coloniais. De acordo com Eduardo Viveiros de Castro, a "inconstância” passou a ser um "traço definidor do caráter ameríndio", consolidando-se como um dos estereótipos do indígena mal convertido (VIVEIROS DE CASTRO, 2002, p. 188). Entretanto, essa característica deve ser entendida como uma "aceitação entusiástica, mas altamente seletiva de um discurso totalizante e exclusivo"(VIVEIROS DE CASTRO, 2002, p. 191), ou seja, as populaçóes indígenas procuraram preservar sua memória, suas tradições, seus costumes, enfim, sua cultura. O fato de absorverem certos elementos da cultura europeia não descaracterizava suas identidades étnicas.

Para que o processo de catequização dos índios obtivesse o sucesso esperado pelos jesuítas nas Missões de Maynas, seria necessário realizar a integração entre os índios reduzidos e os pueblos cristãos, segundo Maroni:

Otro medio muy provechoso para lo mismo, y es, que los que se van poblando tengan comunicacion con alguno pueblo xtiano, y si es factible, salgan á veces á alguna ciudad y lugar de los más cercanos á la montaña, pues con sola la vista del gobierno político que se estila entre cristianos, culto y ornato de las iglesias, respeto y veneracion que tiene el vulgo á los sacerdotes y prelado, aprenden mucho más que con repetidas pláticas y consejos del misionero, y en volviendo á sus tierras, procuran imitar á su modo lo que vieron praticarse en otras partes. (MARONI, 1988, p. 206)

Maroni propunha, assim, a integração entre os índios e os colonos espanhóis residentes nas cidades mais próximas das Missóes de Maynas. Isso efetivamente nunca se concretizou, principalmente porque, mesmo as cidades consideradas mais próximas, como San Francisco de Borja ou Santiago de las Montañas, localizavam-se na região do pé-de-monte andino, portanto, ficavam muito distantes de Maynas, o que dificultava o acesso dos colonos às missóes. Além disso, essas cidades não tinham contingente populacional suficiente para o projeto proposto pelo padre Maroni: 
Los vecinos de la ciudad [San Francisco de Borja] no llegan hoy a treinta mestizos pobres, [...]. Indios tributarios hoy se cuentan apenas cuarenta; almas por todos, doscientas ochenta. El haberse disminuido tanto con varios contratiempos esta ciudad, que ha sido en tiempos antiguos el instrumento principal de todas las conquistas, como también el estar muy retirada de las misiones bajas, ha sido uno de los principales estorbos de que no se hayan adelantado más las misiones, y los piratas portugueses hayan ejecutado cuantas insolencias les ha sugerido su insaciable codicia, sin recelo de resistencia. Uno de los medios que los experimentados reconocen como el más importante para la conservación y adelantamiento de las misiones, es el procurar de aumentar con nuevos vecinos esta ciudad y entablar otra población semejante en la provincia de Omaguas, que sirva de freno a los portugueses, y también a los indios recién convertidos, que llevados de su natural inconstancia a cada paso, burlándose del misionero desamparan las reducciones y vuelven a sus esconderijos. (MARONI, 1988, p. 402)

Maroni deixava explícita a situação precária de San Francisco de Borja e, diante da impossibilidade de obter auxílio desses colonos, propôs, ainda, que se levantasse uma cidade semelhante na Província de Omaguas, região próxima ao rio Negro e extremamente vulnerável às investidas portuguesas. Ora, se os colonos de San Francisco de Borja já encontravam tantas dificuldades para se manterem em sua própria cidade, como mostra o relato de Maroni, é difícil crer que conseguiriam prestar algum tipo de auxílio na fundação de uma nova cidade em uma região tão afastada e hostil.

Outro fator apontado por Maroni em suas Noticias era que essa integração entre colonos e índios seria especialmente produtiva para as crianças e para os jovens indígenas que, aprendendo a língua espanhola, poderiam participar de atividades comerciais com outros povos cristãos. Isso significava que a integração econômica era essencial para o sucesso do projeto jesuítico nas Missões de Maynas e, para que ela fosse efetiva, fazia-se necessária a presença de colonos atuando como auxiliares dos missionários, não apenas formando uma escolta, mas também como residentes, que, dessa forma, serviriam para as populações indígenas como um "modelo de cidadão" para a construção de uma nova sociedade "civilizada”. Porém, como já demonstrado, eram poucos os colonos que se aventuravam por terras consideradas inóspitas e menos ainda os que nelas permaneciam:

Muchas fueron las causas y sucesos funestos que obligaron [á] nuestros misioneros á desistir de la empresa [conquista dos Xíbaros]. La una causa fué la inconstancia de los españoles venidos de Quito para la nueva colonia [Logroño], quienes, extrañando la intemperie del clima y penuria de mantenimientos que es forzosa en los principios de semejantes fundaciones, fueron poco á poco retirandose hasta volver todos para su tierra. (MARONI, 1988, p. 279)

Maroni registrou que, mesmo aqueles que se aventuravam, em pouco tempo acabavam retornando aos seus antigos destinos. Dessa forma, ficava muito difícil aos missionários de Maynas alcançarem o sucesso em seu empreendimento, uma vez que os jesuítas atuavam como os únicos representantes, tanto da autoridade colonial espanhola quanto do modelo civilizacional europeu e cristão. Como afirmou Torres Londoño: "No solo fueron varias veces la primera presencia colonial, sino también muchas veces y durante varios periodos, la única presencia europea en vastas áreas, que dieron a conocer, ya desde aquella época, a través de su abundante producción [...].” (TORRES LONDOÑO, 2012, p. 185).

Por meio desta breve análise das Noticas Auténticas del Famoso rio Marañón, podemos perceber que o Padre Pablo Maroni utilizou seu conhecimento sobre a região e sua experiência como missionário para desenhar uma proposta de desenvolvimento para as Missóes de Maynas que, 
nas primeiras décadas do século XVIII, já dava sinais de decadência, tanto por falta de incentivo, cuidado e interesse da própria coroa espanhola quanto pelas insistentes incursóes portuguesas que visavam à captura de indígenas e ao alargamento de suas fronteiras. Temendo o fim daquele grandioso empreendimento jesuítico, o missionário Pablo Maroni registrou, em suas Noticias, uma proposta para o desenvolvimento das Missóes.

É interessante notar que, em nenhum momento, o padre questionou o modelo jesuítico de missão e tampouco pensou em qualquer outro modelo de ocupação para aquele território. Sua proposta incidia justamente em promover uma melhoria no modelo já aplicado em Maynas. Para tal, destacou dois pontos que, em sua visão, eram fundamentais para o desenvolvimento daquelas missóes: a necessidade de escolta armada para segurança e proteção dos missionários e a fundação de vilas ou povoados de colonos nas áreas próximas às reduçôes. Como Maynas era uma região muito afastada das cidades do pé-de-monte andino e a população de colonos era insuficiente mesmo nas cidades, a proposta de Maroni mostrou-se impraticável.

\section{Considerações finais}

As Missões de Maynas estenderam-se por toda a região do alto Amazonas e estiveram sob o controle dos missionários jesuítas, entre os anos de 1638 e 1767. A experiência dos jesuítas nas Missóes de Maynas mostrou que a realidade das reduçóes na região se distanciava cada vez mais do projeto jesuítico idealizado no início da colonização; para que os missionários tivessem êxito em Maynas, foram necessárias diversas adaptações ao modelo de missão estabelecido pela Companhia de Jesus.

Os jesuítas de Maynas deixaram escritas suas práticas, seus pensamentos, sentimentos, suas descrições, reflexões e outros assuntos que julgaram proveitosos para o desenvolvimento de seu trabalho naquelas missóes. Analisamos aqui uma parte de um desses documentos, as Noticias Auténticas del Famoso Rio Maroñón, obra escrita pelo jesuíta Pablo Maroni e deixada inacabada em 1738.

As Missões de Maynas encontravam-se em uma região periférica do império colonial espanhol, era considerada inóspita por seu clima e pela extensa área de densa floresta que a cobria. Somava-se a isso a enorme diversidade étnica das populações nativas e as frequentes demonstraçóes de hostilidade contra os espanhóis. Além disso, a região era alvo das investidas portuguesas que buscavam tanto a captura de indígenas para o trabalho forçado quanto o alargamento de suas fronteiras. Sendo assim, na maioria das vezes, os jesuítas eram os únicos representantes da autoridade colonial e o projeto missionário da Companhia de Jesus era o único empreendimento visto como viável para a ocupação daquele imenso território.

Entretanto, principalmente por falta de investimentos da coroa espanhola e pelo aumento das investidas lusitanas, as Missões de Maynas entram em declínio no início do século XVIII. O Padre Pablo Maroni vivenciou esse duplo movimento de expansão e declínio das Missões de Maynas e, a partir de suas experiências, registrou, em suas Noticias, sua proposta para o desenvolvimento daquelas missões.

De acordo com Maroni, para o desenvolvimento das Missóes de Maynas, era fundamental a presença de colonos espanhóis nas reduçóes, tanto compondo escoltas armadas para proteção dos missionários quanto vivendo juntamente com os indígenas. Como vimos, a proposta do jesuíta mostrou-se impraticável por conta da escassez de colonos na região. As Missóes de Maynas desapareceram, quase que por completo, após a expulsão dos jesuítas em 1767. 


\section{Referências}

BOXER, Charles R. A Igreja militante e a expansão ibérica:1440-1770. São Paulo: Companhia das Letras, 2007. CASTELNAU- L'ESTOILE, Charlotte. Operários de uma vinha estéril: os jesuítas e a conversão dos índios no Brasil 1580-1620. São Paulo: EDUSC, 2006.

DOWNES, Peter. Jesuitas en la Amazonía: experiencias de Brasil y Quito. In: HERNÁNDEZ PALOMO, José Jesús; MORENO JERIA, Rodrigo (coord.). La Misión y los Jesuítas en la América Española, 1566-1767: Cambios y Permanencias. Sevilla: Consejo Superior de Investigaciones Científicas, Escuela de Estudios Hispano-Americanos, 2005.

EISENBERG, José. As missões jesuíticas e o pensamento político moderno: encontros culturais, aventuras teóricas. Belo Horizonte: Ed. UFMG, 2000.

FIGUEROA, Francisco de S. J. Informe de las Misiones en el Marañón, Gran Paráo Río de las Amazonas (1661). Iquitos: CETA-IIAP, p. 143-309, 1986. [Coleção Monumenta Amazónica, série B-1].

GOLOB, Ann. The Upper Amazon in Historical Perspective. PHD, Nova lorque: Universidade de Nova lorque,1982.

MARONI, Pablo S. J. Noticias Auténticas del Famoso Rio Marañón (1738). Iquitos: CETA-IIAP, p. 87-395, 1988.

[Coleção Monumenta Amazónica, série B-4].

MARTIN RUBIO, Maria del Carmen. Historia de Maynas, un paraiso perdido en el Amazonas (Descripciones de Francisco Requena). Madrid: Ediciones Atlas, 1991.

MARTINS, Maria Cristina Bohn. Sobre “agir muy poco á poco hasta tenellos ganados”: as Instruções do Padre Diego de Torres Bollo para a missão entre os guaranis. In: ALMEIDA, Suely Creusa Cordeiro de; SILVA, Gian Carlo de Melo; RIBEIRO, Marília de Azambuja. Cultura e Sociabilidade no Mundo Atlântico. Recife: Editora Universitária, 2012.

MELIÀ LLITERAS, Bartomeu. Mision por reduccion. Suplemento antropológico. Asunción, v. 6, n. 1, jun. 1991.

MELIÀ LLITERAS, Bartomeu. El Guaraní Conquistado y Reducido: ensayos de etnohistoria. Asunción: Centro de Estudios Antropológicos de la Universidad Católica, 1993.

POMPA, Cristina. Religião como tradução: missionários, Tupi “ “Tapuia” no Brasil Colonial. São Paulo: EDUSC, 2003.

PORRAS, Maria Elena. Gobernacion y Obispado de Mainas (siglos XVII y XVIII). Quito: Abya Yala e Taller de Estudios Historicos (TEHIS), 1987.

SILVA, Giovani José da; NASCIMENTO, Bruno Rafael Machado. Américas Indígenas “Periféricas”: nativos e jesuítas em Oiapoque e Chiquitania. Habitus. Goiânia, v. 15, n. 1, p. 137-158, jan./jun. 2017.

TORRES LONDOÑO, Fernando. A cristianização nos confins. Missionários, soldados, índios amigos e índios a converter. Atores e papéis nas crônicas de Maynas. In: AGNOLIN, Adone; ZERON, Carlos Alberto de Moura Ribeiro; WISSENBACH, Maria Cristina Cortez; MELLO E SOUZA, Marina de. Contextos Missionários: Religião e Poder no Império Português. São Paulo: Editora Hucitec; FAPESP, 2011.

TORRES LONDOÑO, Fernando. Visiones jesuíticas del Amazonas en la Colonia: de la misión como dominio espiritual a la exploración de las riquezas del río vistas como tesoro. Anuario Colombiano de Historia Social y de la Cultura, v. 39, n. 1, p. 183-213, 2012.

TORRES LONDOÑO, Fernando; MARTINS, Fredson Pedro. Jesuítas, indígenas e o código religião nas crônicas de Maynas, Mojos e Chiquitos no século XVIII. Revista História e Cultura. Franca, v. 3, n. 2, p. 188-213, 2014.

VIVEIROS DE CASTRO, Eduardo. A inconstância da alma selvagem - e outros ensaios de antropologia. São Paulo: Cosac \& Naify, 2002.

\section{Notas}

${ }^{1}$ Optamos por utilizar a versão impressa deste documento, publicado na Coleção Monumenta Amazónica, em 1988, pelo CETA e pelo IIAP, em lquitos, Peru. 